\title{
Estudo comparativo dos parâmetros angulares da marcha humana em ambiente aquático e terrestre em indivíduos hígidos adultos jovens
}

\author{
Danieli Isabel Romanovitch Ribas¹, Vera Lúcia Israel1, Elisângela Ferretti Manfra e Camila Costa de Araújo
}

\section{RESUMO}

Há um grande interesse em estudar o movimento humano dentro da água, uma vez que o meio já é utilizado para treinamento e reabilitação devido às diferentes propriedades mecânicas que oferece. No entanto, há uma carência de estudos sobre as características biomecânicas do andar em ambiente aquático. O presente estudo teve como objetivo determinar as variáveis angulares do joelho e tornozelo da marcha em ambiente aquático, e comparálas com o ambiente terrestre. Fizeram parte deste estudo dezenove adultos do sexo masculino, saudáveis, com média de idade de 24 anos. Os indivíduos caminharam em ambiente terrestre e em seguida no ambiente aquático com a água ao nível do processo xifóide do esterno, com velocidade auto-selecionada e confortável. Para a coleta de dados foi utilizada a cinemetria. As variáveis angulares analisadas apresentaram diferenças significativas em ambiente aquático quando comparadas com as do ambiente terrestre. Os resultados encontrados neste estudo contribuem para um melhor entendimento do andar no AA no contexto de treinamento e reabilitação.

\section{ABSTRACT \\ Comparative study of the angular parameters of human gait in water and land media in young higid adults}

There is a great interest to study the human movement under water, once it is a means has been utilized as an alternative way for both training and rehabilitation value owing to different mechanical proprieties it offers. However, there is some information about the biomechanical characteristics of shallow water walking. For collection of the data the cinemetry was used. The present study aims purpose the determination angular characteristics knee and ankle during walking in water and comparing it to the standard of the gait done on land. They were part of this nineteen healthy adults of the sex male with mean 24 years. The individuals walked on land and water with xiphoid process level, with self-selected comfortable walking speeds. The variables joint angles investigated was differences considerably between in shallow water on land. The results in the present study contribute to a better understanding of this activity in the context of training and rehabilitation.

\section{INTRODUÇÃO}

A recuperação cinético-funcional da marcha ocupa um dos principais objetivos no tratamento fisioterapêutico em patologias que afetam os membros inferiores. Por conseqüência, demanda contínuos estudos, especialmente a respeito dos procedimentos de

1. PUCPR, Curitiba/PR

Aceito em 13/6/07.

Endereço para correspondência: Danieli Isabel Romanovitch Ribas, Rua Dro Julio Farah, 135 - 81570010 - Curitiba, PR.

E-mail: danieliribas@yahoo.com.br
Palavras-chave: Fisioterapia. Marcha. Biomecânica. Ambiente aquático.

Keywords: $\quad$ Physical therapy. Gait. Biomechanical. Water.

avaliação, fator que implicará diretamente nos objetivos e intervenções fisioterapêuticas. Com o avanço das formas de avaliação está sendo possível pesquisar a marcha humana em diferentes condições e ambientes, como em gravidade reduzida e no meio aquático(1-4).

A habilidade de andar ereto é uma das características determinantes do ser humano. Rítmico e aparentemente sem esforço, o ato de andar é um evento contínuo que se constitui em transferir peso de um membro inferior para o outro, com o objetivo de avançar o corpo para frente, como se fossem sucessivos desequilíbrios $^{(5)}$

Apesar do controle seletivo e habitual, cada indivíduo apresenta um padrão particular de marcha para se deslocar no ambiente com o mínimo de esforço possível, estabilidade adequada e aparência aceitável(6). Para Rose e Gamble $(1998)^{(7)}$, a marcha humana é uma forma relativamente exclusiva de locomoção, pois ela apresenta eficiência e funcionalidade únicas.

No ser humano normal, um padrão de marcha é adquirido na infância e com a prática, o sistema sensório motor, torna-se muito adaptado e gera automaticamente um conjunto repetitivo de comando de controle motor, para permitir a pessoa caminhar sem esforço consciente ${ }^{(6)}$. De maneira geral, o comportamento motor apresentado por uma criança, adulto ou idoso é o resultado de uma interação de vários fatores que compõe os diversos domínios do comportamento humano(8).

Em decorrência das propriedades físicas e térmicas da água o comportamento das variáveis da marcha em água diferencia-se das do solo(9). De acordo com Israel e Pardo (2000)(10) a água possui efeitos hidrotérmicos e hidromecânicos. Estes efeitos são determinados pela temperatura da água, pelo Princípio de Pascal, pelo Princípio de Arquimedes e pelas resistências da água (que envolve as propriedades do meio líquido: viscosidade, tensão superficial, turbulência de fluxo, entre outras ${ }^{(11-14)}$.

As propriedades físicas da água não só facilitam, mas também resistem a determinados movimentos em imersão de indivíduos com marcha normal, portanto podendo favorecer a reeducação ou mesmo incentivar um padrão não adequado da marcha do paciente. Infantini e Rodrigues (2000)(15) ressaltam que uma avaliação do movimento de segmentos em imersão é de extrema importância para acompanhar a efetividade do tratamento proposto.

O conhecimento de variáveis cinemáticas durante a execução da marcha em terra e água, pode ajudar a entender o comportamento motor quando em interação com estes meios e influenciar no diagnóstico cinético-funcional e no tratamento fisioterapêutico.

Levando em consideração que a avaliação fisioterapêutica deve buscar embasamento em dados mensuráveis e não somente em observações subjetivas e que há poucos estudos relacionando variáveis biomecânicas em meio aquático, o presente estudo teve 
como objetivo analisar a marcha de indivíduos saudáveis em ambiente aquático e terrestre, a fim de verificar as possíveis diferenças entre os meios em relação as alterações nos parâmetros cinemáticos angulares da articulação do joelho e do tornozelo nas fases e subfases da marcha.

Pretende-se com este estudo contribuir para o avanço do conhecimento existente sobre o assunto proposto e, ao mesmo tempo, auxiliar na avaliação e evolução do tratamento fisioterapêutico de indivíduos que necessitam da recuperação cinético-funcional da marcha.

\section{METODOLOGIA}

O presente estudo foi realizado nos setores de Hidroterapia da Clínica Escola do Curso de Fisioterapia, no Laboratório de Comunicação Social e no Laboratório de Engenharia de Reabilitação da Pontifícia Universidade Católica do Paraná, na cidade de Curitiba. O período da coleta de dados foi de janeiro de 2006 a fevereiro de 2006.

Participaram deste estudo 19 indivíduos hígidos, voluntários, do sexo masculino, maiores de 18 anos.

Este estudo respeitou a Resolução 196/96 do Conselho Nacional da Saúde e foi aprovado pelo Comitê de Ética em Pesquisa da PUCPR sob o registro no 424. Cada indivíduo tomou conhecimento do procedimento a ser realizado e assinou um termo de consentimento livre e esclarecido.

Os critérios de inclusão foram: indivíduos adultos jovens do sexo masculino com ausência de alterações no padrão da marcha e sem limitações físicas dos sistemas osteomioarticulares, nervoso e/ou cardiopulmonar diagnosticados.

Os critérios de exclusão foram: impossibilidade de participar de uma das etapas da pesquisa, contra-indicações absolutas e relativas do ambiente aquático prevista pela literatura.

Para a realização da coleta de dados os sujeitos que se dispuseram fazer parte do estudo foram submetidos inicialmente a uma seleção, denominada etapa (a). Os sujeitos selecionados foram submetidos a coleta de dados da marcha em ambiente terrestre (etapa b) e em ambiente aquático (etapa c).

Para a seleção dos sujeitos foi utilizada uma ficha de avaliação elaborada para o estudo. Por meio desta ficha foram coletados os seguintes dados: nome (registrado de maneira codificada), sexo, idade, peso, altura, índice de massa corpórea (IMC), anamnese, avaliação subjetiva da marcha através da observação e registro dos ângulos articulares de flexão/extensão de quadril, joelho e tornozelo, obtidos através da goniometria.

Para a análise da marcha e posterior cálculo dos ângulos articulares em ambiente terrestre e aquático foi necessário marcar pontos anatômicos nos indivíduos através do uso de marcadores passivos. A escolha destes pontos foi baseada no modelo bidimensional de quatro segmentos ${ }^{(16)}$. Por meio deste modelo os membros superiores e o tronco são representados como um único segmento denominado CBT (cabeça, braços e tronco), e o membro inferior dividido em três segmentos: coxa, perna e pé. Os segmentos são delimitados por pontos localizados em estruturas anatômicas: maléolo lateral, cabeça do V metatarso, côndilo femoral lateral, trocânter maior do fêmur e acrômio, e todos os pontos estão referenciados a um mesmo sistema de coordenadas.

Os pontos marcados nos indivíduos, e a definição dos ângulos, de acordo com o modelo utilizado podem ser visualizados na figura 1.

Os marcadores utilizados eram da cor branca, a prova d'água com dimensões iguais a $3,5 \mathrm{~cm} \times 3,5 \mathrm{~cm}$. Para a filmagem da marcha em solo, foi posicionada no plano sagital, uma câmera digital (a) a uma distância de 4,20m da passarela, e a $1 \mathrm{~m}$ do solo, com eixo óptico perpendicular ao plano de deslocamento.

Dentro do plano de visão da câmera de vídeo utilizada foi posicionado um objeto de calibragem de dimensões igual a $1,60 \mathrm{~m} \times$
$2,00 \mathrm{~m}$ (comprimento e altura respectivamente) com 30 pontos espaçados. Este calibrador foi posicionado dentro do plano de visão das câmeras e permitiu recuperar as dimensões reais dos segmentos corporais a partir das imagens digitalizadas.

Cada indivíduo foi orientado a caminhar, a uma velocidade de sua própria escolha em uma passarela de $4,0 \times 1,10 \mathrm{~m}$ de comprimento e largura respectivamente, delimitada com fita adesiva.

Esta etapa foi realizada no Laboratório de Comunicação Social da PUCPR e o arranjo experimental para esta etapa pode ser visualizado na figura 2.

Após a avaliação da marcha em solo os participantes foram submetidos à avaliação da marcha em ambiente aquático no setor de Hidroterapia da Clínica Escola do Curso de Fisioterapia da PUCPR em uma piscina com dimensões iguais a 4,0m $\times 6,0 \mathrm{~m}$ de largura e comprimento respectivamente. O nível da água foi mantido no processo xifóide.

Para a aquisição das imagens nesse ambiente foram utilizadas duas câmeras de vídeo digital. Uma das câmeras (a) foi inserida em uma caixa estanque da marca Croma, e posicionada no interior da piscina a uma distância de $5 \mathrm{~m}$ de comprimento da passarela utilizada pelos participantes. A outra câmera (b) foi posicionada fora da piscina a uma distância de 6,0m de comprimento da borda contra lateral a passarela. A passarela em ambiente aquático foi demarcada com uso de fita adesiva nas bordas externas da piscina.

No plano de visão das câmeras foi posicionado o mesmo calibrador utilizado em ambiente terrestre.

Cada indivíduo foi orientado a caminhar em uma passarela de $4,0 \mathrm{~m} \times 0,75 \mathrm{~m}$ de comprimento e largura respectivamente, a uma velocidade de sua própria escolha.

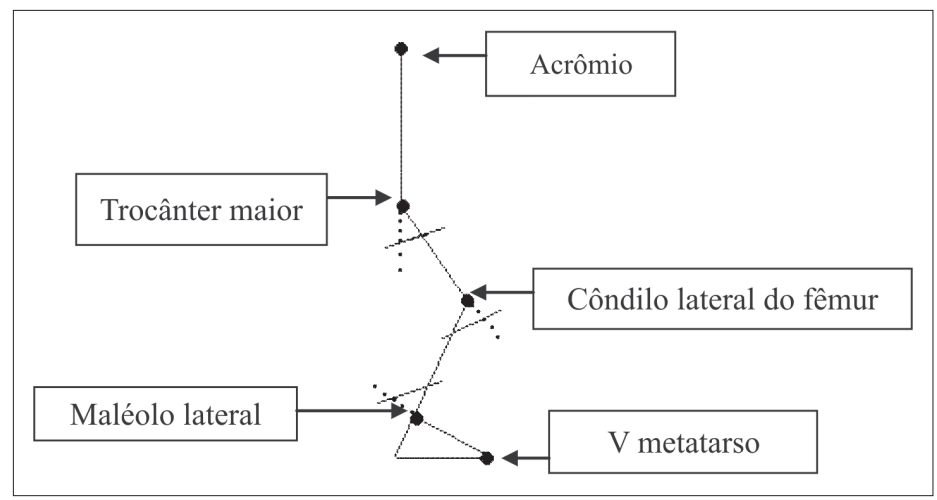

Figura 1 - Marcação dos pontos anatômicos e definição dos ângulos de acordo com o modelo dos quatro segmentos

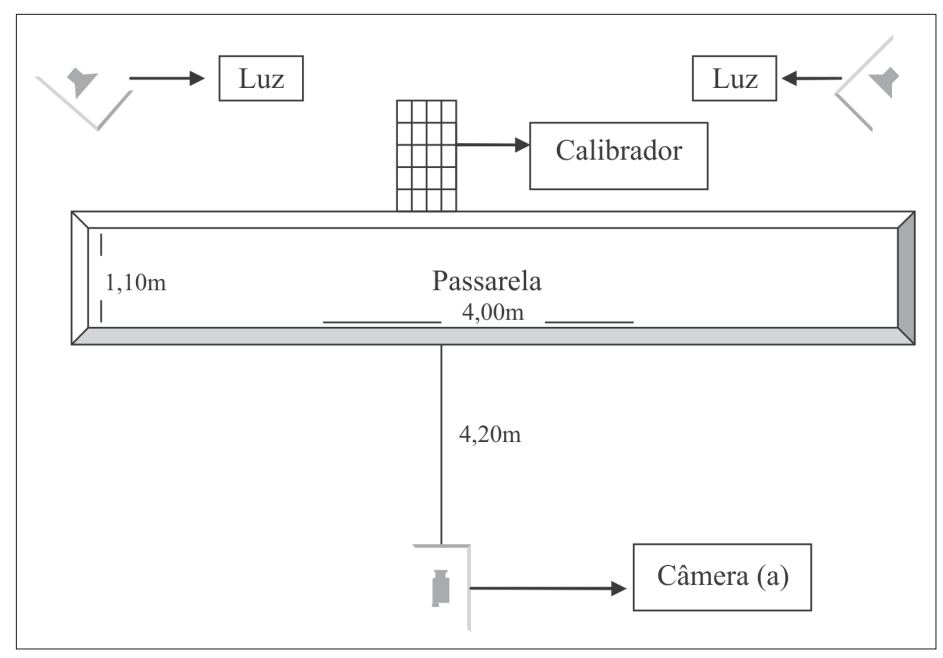

Figura 2 - Representação esquemática do arranjo experimental para aquisição dos dados em ambiente terrestre (AT) 
O arranjo experimental para esta etapa pode ser visualizado na figura 3.

Antes de iniciar a aquisição das imagens em ambos os ambientes cada participante foi ambientado à atividade a ser realizada, executando a atividade de caminhar quantas vezes julgassem necessárias.

Após as aquisições das imagens em ambiente aquático e terrestre, estas foram transferidas para um computador com o auxílio do software Adobe Premier-Pro versão 7.0.

Para cada sujeito foram selecionados 3 ciclos de marcha. Em cada frame do ciclo da marcha, as posições dos marcadores foram recuperadas utilizando um programa desenvolvido pelo grupo de pesquisa no ambiente MATLAB (figura 4)(17). O procedimento para a transformação das coordenadas reais dos dados adquiridos foi por meio do método de calibração de transformação linear direta (DLT, "direct linear transformation"). As imagens

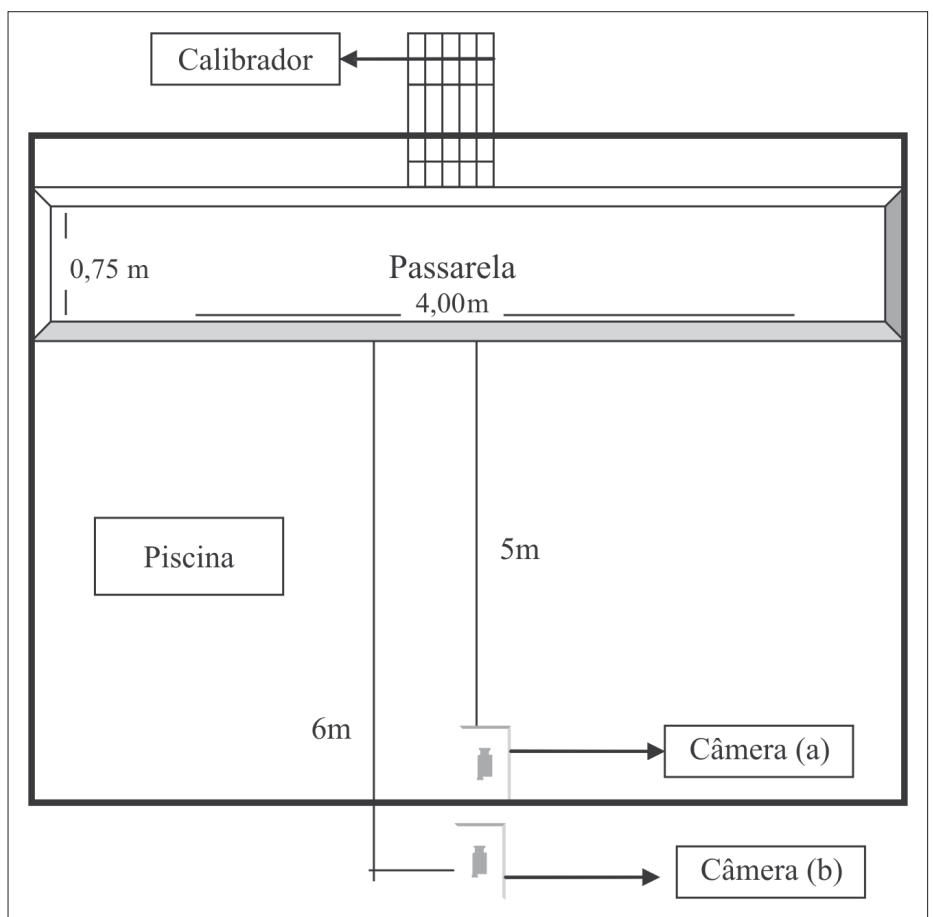

Figura 3 - Representação esquemática do arranjo experimental para aquisição dos dados em ambiente aquático (AA)

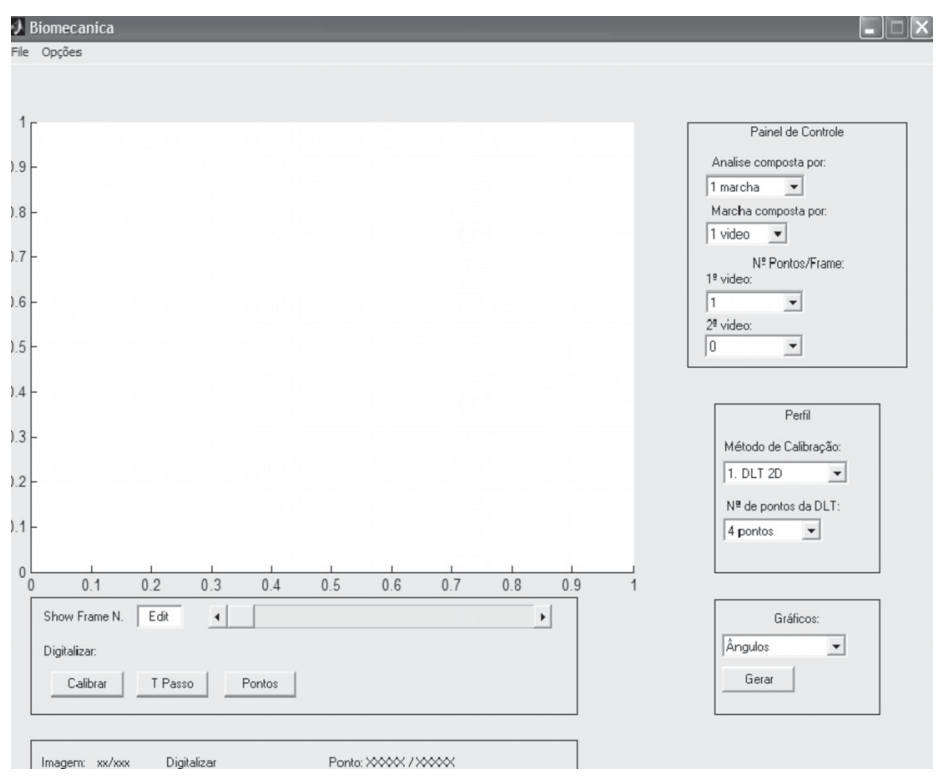

Figura 4 - Tela inicial do Programa de análise da marcha solo-água provenientes das duas filmadoras foram sincronizadas automaticamente pelo software.

Uma vez recuperadas as coordenadas foi possível calcular as trajetória do ângulos articulares do joelho e tornozelo. Os dados obtidos foram filtrados com um filtro passa-baixa de ordem 10, com freqüência de corte de $1.5 \mathrm{~Hz}$.

Para a análise das variáveis angulares em ambiente terrestre e aquático o ciclo da marcha $(100 \%)$ foi dividido em suas fases e subfases $^{(7)}$. Considerou-se que a fase de apoio e balanço para o ambiente aquático e terrestre era de $60 \%$ e $40 \%$ respectivamente.

A fase de apoio equivalente a $60 \%$ do ciclo foi subdividida em fase de apoio inicial (10\% iniciais do ciclo), apoio médio (10\% a $30 \%$ do ciclo), apoio final (30\% a $60 \%$ do ciclo). A fase de balanço correspondente aos $40 \%$ finais do ciclo da marcha subdividido em: balanço inicial (60 a 73\% do ciclo), balanço médio $(73 \%$ a $87 \%$ do ciclo) e balanço final ( $87 \%$ a $100 \%$ do ciclo).

Após aquisição dos resultados, foram empregadas técnicas de estatística descritivas, sendo estas separadas em: medidas de posição e tendência central e medidas de variabilidade.

Foram aplicados os testes de Shapiro - Wilk, Teste de Fisher e Teste $t$ - pareado. O nível de confiança para estes testes foi fixado em $95 \%(p<0,05)$.

\section{RESULTADOS}

Na tabela 1 podemos verificar a caracterização da amostra por meio da média da idade, peso, altura e índice de massa corpórea e os respectivos desvios padrões dos sujeitos que participaram do estudo.

As curvas médias dos ângulos do joelho em ambiente aquático (AA) e ambiente terrestre (AT) podem ser visualizados no gráfico 1.

De acordo com o Teste Shapiro Wilk, a articulação do joelho apresenta distribuição normal $(p<0,05)$. O Teste de Fisher não mostrou diferença significativa entre as variâncias para o ângulo articular na fase de apoio médio e apoio final e oscilação final com nível de confiança de 95\%.

O Teste $t$ - pareado não mostrou diferença significativa $(p<0,05)$ para a articulação do joelho durante o balanço inicial. Para as de-

TABELA 1

Média da idade, altura, peso dos sujeitos participantes da pesquisa $(n=19)$

\begin{tabular}{lcccc} 
& Idade (anos) & Altura (m) & Peso (kg) & IMC $\left(\mathbf{k g} / \mathbf{m}^{2}\right)$ \\
Media & 24,11 & 1,75 & 69,63 & 22,72 \\
DV & $\pm 3,26$ & $\pm 0,05$ & $\pm 8,44$ & $\pm 2,19$ \\
\hline
\end{tabular}

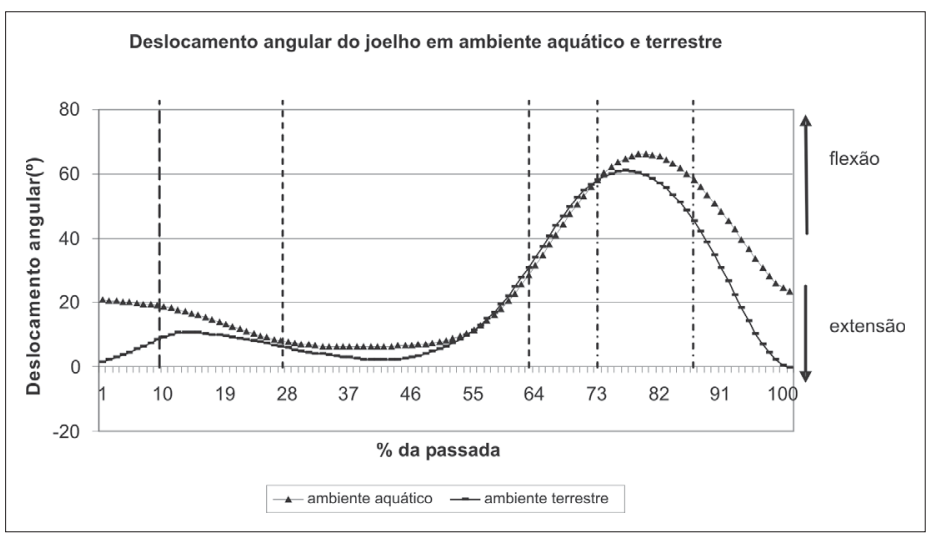

Gráfico 1 - Curvas médias dos ângulos articulares do joelho em ambiente terrestre e aquático. As linhas verticais indicam da esquerda para a direita as subfases da marcha: apoio inicial, médio e final, e balanço inicial, médio e final. 


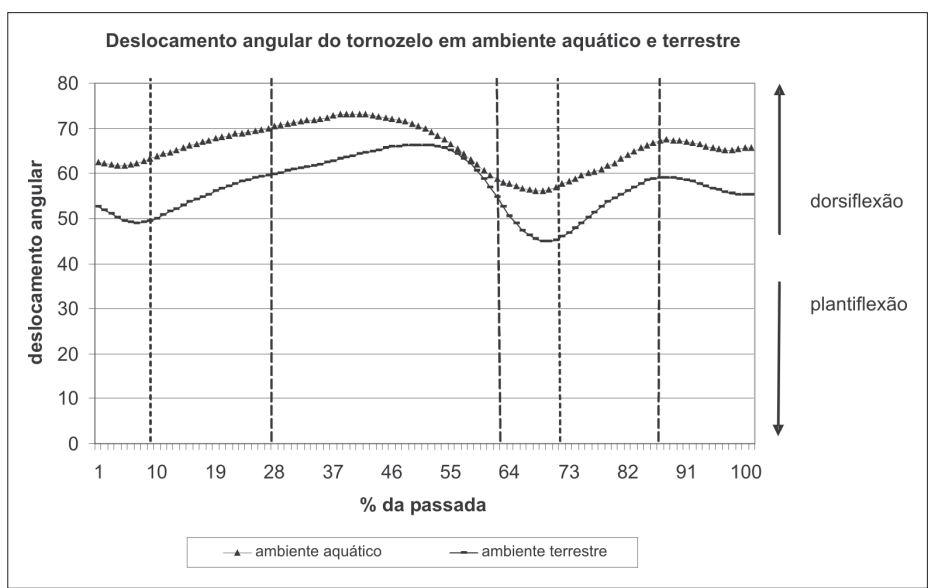

Gráfico 2 - Curvas médias dos ângulos do tornozelo em ambiente aquático (AA) e terrestre (AT). As linhas verticais indicam da esquerda para direita as subfases da marcha: apoio inicial, médio e final e oscilação inicial, média e final.

\section{TABELA 2}

Média dos valores angulares da articulação do joelho e tornozelo em um ciclo de marcha

\begin{tabular}{|c|c|c|c|c|}
\hline \multirow[t]{2}{*}{ Ângulos } & \multicolumn{2}{|c|}{ Joelho } & \multicolumn{2}{|c|}{ Tornozelo } \\
\hline & AT & AA & AT & AA \\
\hline Apoio inicial & $5,11 \pm 4,44$ & $19,88 \pm 9,98$ & $49,94 \pm 3,44$ & $62,24 \pm 5,91$ \\
\hline Apoio médio & $8,66 \pm 5,42$ & $12,34 \pm 6,46$ & $56,42 \pm 3,97$ & $67,93 \pm 4,58$ \\
\hline Apoio final & $6,29 \pm 3,79$ & $8,52 \pm 3,18$ & $64,03 \pm 4,69$ & $70,12 \pm 4,78$ \\
\hline Balanço inicial & $43,12 \pm 5,82$ & $40,92 \pm 14,43$ & $47,99 \pm 4,53$ & $57,04 \pm 6,95$ \\
\hline Balanço médio & $57,13 \pm 3,07$ & $63,94 \pm 17,57$ & $54,58 \pm 4,05$ & $63,03 \pm 7,02$ \\
\hline Balanço final & $17,57 \pm 5,60$ & $38,22 \pm 8,89$ & $57,01 \pm 3,29$ & $66,16 \pm 4,57$ \\
\hline
\end{tabular}

mais subfases do ciclo da marcha houve diferença significativa ( $p$ $<0,05)$.

Para a articulação do tornozelo, os valores obtidos durante um ciclo de marcha, podem ser visualizados no gráfico 2. Os valores são positivos tanto para a dorsiflexão quanto para plantiflexão, de acordo com o modelo usado nesta pesquisa. O ângulo de referência para a indicação de posicionamento será de aproximadamente de $60^{\circ}$.

Pelo Teste de Shapiro Wilk a articulação do tornozelo segue o modelo de distribuição normal $(p<0,05)$. O Teste de Fisher indicou diferença de variância significativa $(p<0,05)$ para o ângulo do tornozelo durante o apoio inicial e balanço médio.

De acordo com o Teste $t$ - pareado os ângulos articulares do tornozelo apresentaram diferença significativa durante todas as subfases da marcha humana, entre o ambiente aquático e terrestre $(p<0,05)$.

Os ângulos articulares para a articulação do joelho e tornozelo podem ser visualizados na tabela 2 .

\section{DISCUSSÃo}

Aceita-se por partes dos profissionais que trabalham com a hidroterapia que existem diferenças na cinemática da marcha quando esta é realizada em ambiente aquático e terrestre, porém há poucos estudos destinados à análise das variações biomecânicas neste ambiente $e^{(9,14,25,27)}$

Neste estudo realizou-se a análise da marcha separando-a em suas fases e subfases, sendo possível verificar em que subfase ocorre maior diferença entre os ambientes.

Ao comparar o movimento da articulação do joelho em ambiente aquático (AA) e ambiente terrestre (AT) percebe-se que durante o apoio inicial e oscilação final a extensão articular em AT é maior quando comparada com o AA.
Durante a oscilação inicial e média a articulação tanto em AT como em AA realizaram flexão. A flexão máxima para a água e para o solo foi durante a oscilação média, sendo a flexão do joelho em AA maior do que a flexão em AT.

Os resultados encontrados para o AT confirmam outros estudos $^{(7,18-20)}$, que colocam que durante a fase de apoio inicial o joelho está em extensão progredindo para uma flexão, sendo levado novamente para uma extensão no apoio médio. No balanço inicial o joelho encontra-se em flexão, alcançando seu máximo de flexão no balanço médio e retornando a extensão no final da fase de balanço terminal(16).

Os resultados obtidos para o AA, nesta pesquisa, vão ao encontro aos achados de Yamamoto (1995 apud Ervilha 1999)(21) e Miyoshi et al. (2003 e 2004) ${ }^{(22-23)}$ que encontraram diferenças para o movimento do joelho em água quando comparado com o AT. Estes autores relatam que no apoio inicial em ambiente aquático o joeIho está em flexão.

Outro estudo que confirma os achados nesta pesquisa é de Infantini e Rodrigues (2000)(15) que realizaram um estudo qualitativo com um indivíduo, saudável do sexo feminino e encontraram para a fase de apoio inicial e oscilação média aumento da flexão do joelho.

Os resultados do presente estudo diferem-se dos encontrados por Barela; Stolf e Duarte (2005)(24), que não acharam diferenças para o padrão de movimento do joelho em AA e AT. Encontraram uma flexão em AA menor em relação ao AT durante os 15\% iniciais do ciclo da marcha e quando compararam a flexão encontrada para a fase de oscilação média, em água essa flexão também foi menor.

A variação angular encontrada neste estudo para os dois ambientes assemelha-se a outros estudos de que encontraram diferença significativa para a variação angular do joelho entre a água e o solo(25-26).

Este aumento da flexão do joelho no ambiente aquático pode ser em decorrência a resistência frontal imposta pelo meio líquido. Na tentativa de diminuir esta resistência frontal, os sujeitos em ambiente aquático realizam aumento da flexão da articulação do joelho, uma vez que a extensão da articulação aumentaria esta resistência.

Em relação à articulação do tornozelo, o comportamento do movimento encontrado em água se difere do apresentado em solo.

$\mathrm{Na}$ fase de apoio inicial em AT os indivíduos realizam durante o apoio do calcanhar, dorsiflexão do tornozelo que diminui até a posição neutra articular na fase de apoio médio. No apoio final a articulação está em plantiflexão e à medida que a fase de oscilação ocorre a articulação passa novamente para uma posição neutra até o balanço final, onde novamente estará em dorsiflexão(7,18-20).

Para o AA o pé foi mantido aplanado com a superfície durante o apoio inicial e médio, apresentando um posicionamento muito próximo ao neutro, não ocorrendo apoio do calcanhar durante a subfase de apoio inicial. Barela, Stolf e Duarte (2005)(24) também acharam que a articulação do tornozelo em AA está praticamente neutra durante o apoio inicial. Outros estudos ${ }^{(22-23)}$ encontraram um pico de dorsiflexão no apoio médio para a água e Infantini e Rodrigues (2000)(15) acharam qualitativamente que o tornozelo apresenta em AA uma diminuição da dorsiflexão no apoio inicial.

$\mathrm{Na}$ oscilação inicial ocorre aumento da plantiflexão do tornozeIo, sendo que esta foi menor em AA. Esses achados são diferentes aos encontrados em outros estudos ${ }^{(15,24,27-28)}$. A partir do apoio médio até o apoio final ocorre variação angular maior do tornozelo em direção a plantiflexão e esta aumenta significativamente neste período(27-28).

Barela, Stolf e Duarte (2005)(24) acharam que durante os $60 \%$ da fase de apoio e oscilação final a plantiflexão encontrada para o tornozelo em água foi maior quando comparada com a achada para o solo. 
Estudos anteriores ${ }^{(21-22,24)}$, constataram que a atividade elétrica do músculo tibial anterior, músculo responsável pela dorsiflexão, era menor em ambiente aquático. Isto pode explicar a ausência do toque do calcanhar no solo durante a fase de apoio inicial.

Pode-se deduzir que os sujeitos em AA buscaram maior contato com a superfície para garantir maior estabilidade e equilíbrio.

Mecanicamente o aumento da flexão do joelho que ocorreu em AA promoveu diminuição da inércia angular o que facilitou a rotação do segmento e o apoio do mesmo na superfície, não sendo necessário a realização da dorsiflexão durante o apoio inicial.

Para um movimento angular, quanto maior a distância de um ponto a um eixo de giro maior a velocidade linear deste ponto. A força de arrasto na água é relacionada ao quadrado da velocidade que gera forças de magnitudes diferenciadas para diferentes segmentos corporais que executam um movimento(4). No caso da marcha, o segmento de maior velocidade é o tornozelo por ser a articulação mais distante do centro de giro (quadril). Portanto, isso pode fazer com que o tornozelo adote uma posição angular para flexão, visando minimizar a resistência ao avanço devido à redução da área frontal do pé.

A resistência frontal e o arrasto podem promover uma redução da força de reação do solo(24) e alteram a posição do centro de gravidade aparente ${ }^{(4)}$. Com isso, o movimento pendular do centro de gravidade que caracteriza a marcha no ambiente terrestre é modificado no ambiente aquático, fazendo com que o corpo adote posições angulares diferenciadas para compensar a projeção do centro de gravidade alterada e facilitar o aumento do trabalho muscular que gera o impulso do pé e desloque o corpo para frente.

\section{CONCLUSÃO}

Com a realização deste estudo conclui-se que a marcha em ambiente aquático apresenta diferenças em relação ao comportamento articular em suas fases e subfases em relação ao ambiente terrestre, que devem ser consideradas durante a elaboração de um programa de tratamento que utilize a hidroterapia como recurso.

O deslocamento angular do joelho e tornozelo em ambiente aquático apresentou diferenças em relação ao ambiente terrestre durante todo o ciclo de marcha. Em ambiente aquático a articulação do joelho realizou extensão articular menor a realizada em ambiente terrestre e a articulação do tornozelo não realizou apoio do calcanhar mantendo-se em posição de neutralidade principalmente durante a subfase de apoio inicial.

Essas diferenças podem ser atribuídas ao fato que o corpo humano adota padrões de movimento e estratégias motoras diferentes ao caminhar em ambiente aquático. Isso ocorre, provavelmente, em função da necessidade de adaptar o sistema sensório-motor para deambular em um meio com características físicas diferentes das habituais. A falta de familiaridade e as condições ambientais impostas pelo meio líquido promoveram adaptações ao movimento da marcha em ambiente aquático, para que esta fosse bem sucedida no novo ambiente.

Os resultados obtidos neste estudo em relação as variáveis angulares proporcionam um melhor entendimento por parte dos fisioterapeutas do movimento da marcha humana, colaborando, desta forma, para a elaboração de um programa de reabilitação aquática adequada às necessidades de seus pacientes.

Os maiores benefícios para o paciente estariam na combinação de exercícios nos ambientes aquático e terrestre, pois isto permite que o paciente realize movimentos com amplitude e padrões diferenciados, trazendo possibilidades terapêuticas que viabilizam uma recuperação cinético-funcional de forma mais precoce e completa.

Todos os autores declararam não haver qualquer potencial conflito de interesses referente a este artigo.

\section{REFERÊNCIAS}

1. Campos MH. Aspectos biomecânicos do andar e do correr em meio aquático. São Paulo, 2001. Monografia (Bacharel em Esportes) - Universidade de São Paulo.

2. Griffin TM, Tolani TM, Kram R. Walking in simulated reduced gravity: mechanical energy fluctuations and exchange. J Appl Physiol. 1999;86:383-90.

3. Schütz GR, Haupenthal A, Roesler H. Estudio dinamométrico de la marcha humana en el medio acuático. Revista Digital. 2005:81. http:/www.efdeportes.com> Acesso em: Outubro, 2005

4. Duarte M. Princípios físicos da interação entre ser humano e ambiente aquático. http: www.usp.br/eef/lob/mario01.pdf>. Acesso em: Outubro, 2005

5. Alonso VK, Okaji SS, Pinheiro MT, Ribeiro CM, Souza HP, Santos SS, et al. Análise cinemática da marcha em pacientes hemiparéticos. Revista Fisio Brasil. 2002 55:16-23.

6. Alencar JF, Marino LF, Lucena BA, Gomes J, Medeiros ML. Análise cinemática da marcha em pacientes hemiparéticos tratados no serviço de fisioterapia da UFPB. Anais do VIII Congresso de Biomecânica; 1999. p. 197-202.

7. Rose J, Gamble JG. Human walking. 2nd ed. Baltimore: Williams \& Wilkins; 1994

8; Sutherland DH, Kaufman KR, Moitoza JR. Kinematics of normal human walking In: Rose J, Gamble JG, editors. Human walking. 2nd. Baltimore: Williams e Wilkins; 1994. p. 23-44

9. Roesler H, Brito RN, Haupenthal A, Souza PV. Análise comparativa da marcha humana em solo à subaquática em dois níveis de imersão: joelho e quadril. Revista Brasileira de Fisioterapia. 2004;8:1-6

10. Israel VL, Pardo MBL. Hidroterapia: proposta de um programa de ensino no trabaIho com lesado medular em piscina térmica. Revista Fisioterapia em Movimento. 2000;13:111-27.

11. Bates A, Hanson N. Exercícios aquáticos terapêuticos. 1a edição. São Paulo: Manole; 1998.

12. Campion MR. Hidroterapia: princípios e prática. São Paulo: Manole; 2000

13. Becker BE, Cole AJ. Terapia aquática moderna. São Paulo: Manole; 2000

14. Harrison RA, Hillman M, Bustrode S. Loading of the lower limb when walking partially immersed: implications for clinical practice. Physioterapy. 1992;3:164-7

15. Infantini RM, Rodrigues E. Descrição cinemática qualitativa da marcha normal dentro da água. Revista Fisioterapia UNICID. 2000;1:37-44.

16. Winter D. Biomechanics and motor control of human movement. 3rd ed. New York: A Wiley Interscience Publication JohnWiley e Sons; 2004.

17. Vazatta LD, Mello RGS, Araújo C, Manffra EF. Software para análise cinemática da marcha humana em ambiente terrestre e aquático. Anais do XX Congresso Brasileiro de Engenharia Biomédica; 2006.

18. Greve JMA, Amatuzzi MM. Medicina de reabilitação aplicada à ortopedia e traumatologia. São Paulo: Roca; 1999.

19. Barros TETF, Lech O. Exame físico em ortopedia. São Paulo: Sarvier; 2001.

20. Nymark JR, Balmer SJ, Melis EH, Lemaire ED, Millar S. Electromyographic and knematic nondisabled gait differences at extremely slow overground and treadmill walking speeds. Journal of Rehabilitation Research e Development. 2005; 42:523-34.

21. Ervilha UF. Estudo da variação angular da articulação do joelho e do sinal eletromiográfico no domínio temporal durante a marcha humana em ambiente aquático. Dissertação. Escola de Educação Física e Esporte da Universidade de São Paulo. São Paulo; 1999

22. Miyoshi T, Shirota T, Yamamoto SI, Nakazawa K, Akaia M. Lower limb joint moment during walking in water. Disability and Rehabilitation. 2003;25:1219-23.

23. Miyoshi T, Shirota T, Yamamoto SI, Nakazawa K, Akaia M. Effect of the walking speed to the lower limb joint angulas displacements, joint moments and ground reaction forcer during walking in water. Disability and Rehabilitation. 2004;26: 724-32.

24. Barela AMF, Stolf SF, Duarte M. Biomechanical characteristics of adults walking in shallow water and land. Journal of Electromyography and Kinesiology. 2005; 16:250-6.

25. Ervilha UF, Duarte M, Amandio AC. Padrão do sinal eletromiográfico de músculos do membro inferior e cinemática do joelho durante o andar em ambiente aquático e terrestre. Anais do IX Congresso Brasileiro de Biomecânica, 2001;2: 290-4

26. Ervilha UF, Duarte M, Amandio AC. Cinemática da articulação do joelho e atividade eletromiográfica de músculo do membro inferior durante a marcha em ambiente aquático e terrestre. Revista Brasileira de Biomecânica. 2002;3:21-6.

27. Gehm F, Becker RA, Martinez FG, Loss JF. Análise cinemática da marcha humana em ambiente aquático - Parte I: Terra x Água. Anais do X Congresso Brasileiro de Biomecânica; 2003. p. 107-10

28. Becker RA, Gehm F, Martinez FG, Loss JF. Análise cinemática da marcha humana em ambiente aquático - Parte II: diferentes profundidades. Anais do X Congresso Brasileiro de Biomecânica: 2003. p. 111-4 